\title{
Improving Transformer Protection by Detecting Internal Incipient Faults
}

\author{
A. Ashrafian, M. Rostami, G. B. Gharehpetian, and S. S. Shafiee Bahnamiri
}

\begin{abstract}
This paper proposes a new S-Transform (ST) based method for protection of power transformers by considering internal incipient faults. $\mathrm{S}$-transform is a powerful analytical tool that has the property of Fourier and wavelet transforms. The Hyperbolic S-Transform (HST) is used to extract features of inrush current, internal and internal incipient faults, from the differential currents. A decision has been made using extracted features to discriminate internal incipient faults, magnetizing inrush currents and internal faults. In order to study the efficiency of the proposed method, it is implemented in MATLAB environment and tested with simulated faults and inrush cases under EMTP software. In order to simulate internal turn to turn, turn to earth and internal incipient faults, the transformer is modeled using $8 \times 8$ RL matrices obtained from the subroutine BCTRAN of EMTP software. The signals are infected with noise and the performance of the algorithm in noisy environments is studied.
\end{abstract}

Index Terms-Incipient fault, inrush current, protection, s-transform, transformer.

\section{INTRODUCTION}

The power transformer is an important component of the overall elements of the power system. The transformer protection is an essential part of the system protection. 70-80 percent of the failures in transformers which occur over a period of years are finally caused by short circuits between turns. On-line condition monitoring of transformers can provide early warning of electrical failure and could prevent catastrophic losses [1]. Mostly, there is an aging-arcing process before a turn to turn short circuit. This process is called incipient fault. So, detection of internal incipient fault in power transformer is an early warning of internal fault. Several algorithms are proposed to discriminate between different transient phenomena in transformers. In [2] a gas analysis based algorithm has been proposed. This method is off-line. In [3] an algorithm based on neural networks is presented for detection and classification of internal faults. A transformer fault detection methods based on wavelet transform and correlation factor has been suggested in [4].

Manuscript February 1, 2012; revised March 12, 2012.

A. Ashrafian is with the Department of Engineering, Shahed University Tehran, Iran and Department of Engineering, Shahre-rey branch, Islamic Azad University, Tehran, Iran. (e-mail: a.ashrafian@ieee.org).

M. Rostami is with the Department of Engineering, Shahed University, Tehran, Iran (e-mail: rostami@shahed.ac.ir).

G. B. Gharehpetian is with the Electrical Engineering Department Amirkabir University of TechAnology, Tehran, Iran (e-mail: grptian@aut.ac.ir).

S. S. Shafiee Bahnamiri is with the Department of Engineering, Shahed University, Tehran, Iran And Islamic Azad University, Joubar Branch, Joubar, Iran (e-mail: Shafiee@shahed.ac.ir).
The internal incipient fault is not studied in [3]-[4]. In [5]-[6] discrete wavelet transform based algorithms for discriminating the incipient faults have been suggested. These schemes are influenced by noise because of using wavelet transform. Also, the frequency properties of the decomposition filter band are not ideal and suffer leakage effect where the frequency of the analyzed signal is close to the edge of a frequency band [7]. Since the ST is less influenced by noise, S-transform based algorithms have been proposed for overcoming the noise problems in [7]-[10]. In these methods the internal incipient, the turn to turn, the turn to earth faults is not studied.

In this paper an S-transform based scheme for distinguishing between inrush current, internal incipient fault, internal short circuit and internal faults while transformer energization, is suggested. The ST has been used and the differential currents of the faulty phases are analyzed. A decision has been devised using the standard deviation and the spectral energy of the S-matrix to discriminate different transient phenomena in transformer. Unlike algorithms that use wavelet transform, the proposed algorithm is not affected by noise. The suggested method is capable of distinguishing between incipient fault current and other transient current in transformers even in noisy environments.

\section{REVIEW OF S-TRANSFORM}

Continues Wavelet Transform (CWT) of a time series signal $u(t)$ can be defined as series of correlation of the time series with a wavelet function:

$$
C W T=\int_{-\infty}^{+\infty} u(t) w(\tau-t, a) d t
$$

The S-transform of function $u(t)$ can be defined as a CWT with a specific wavelet multiplied by a phase factor. The S-transform, suggested by Stockwell et al. [11], of a time series $u(t)$ is:

$$
S(\tau, f)=\int_{-\infty}^{+\infty} u(t)\left[\begin{array}{l}
|f| / \sqrt{2 \pi} \\
\times \exp \left(-f^{2}(\tau-t)^{2} / 2\right) \\
\times \exp (-2 \pi i f t)
\end{array}\right] d t
$$

where $S$ is the S-transform of $u(t)$, which is a signal varying with time, $\tau$ is a parameter which controls the position of Gaussian window on the time axis and $f$ denotes the 
frequency. The ST is a time-frequency analysis technique, containing features of both wavelet transform and Short Time Fourier Transform (STFT). The ST is not a wavelet transform, because the oscillatory function. The generalized $\mathrm{S}$-transform is obtained from original S-transform by replacing the Gaussian window with a generalized window [11]:

$$
S(\tau, f, p)=\int_{-\infty}^{+\infty} u(t) w(\tau-t, f, p) \exp (2 \pi i f t) d t
$$

where $p$ denotes a set of parameter that govern the shape of window. S-transform windows must satisfy (4):

$$
\int_{-\infty}^{+\infty} w(\tau-t, f, p) d \tau=1
$$

Because of (4), averaging of ST over all values of $\tau$ is Fourier transform of $u(t)$, therefore, provides a join between ST and Fourier transform and guarantee that ST is invertible:

$$
\begin{aligned}
& \int_{-\infty}^{+\infty} S(\tau, f, p) d \tau=\int_{-\infty}^{+\infty} u(t) \exp (-2 \pi i f t) \times \\
& \int_{-\infty}^{+\infty} w(\tau-t, f, p) d \tau d t=\int_{-\infty}^{+\infty} u(t) \exp (-2 \pi i f t) d t \\
& =U(f)
\end{aligned}
$$

The hyperbolic S-transform is obtained from the generalized S-transform, by replacing the generalized window with a hyperbolic window [9]:

$$
\begin{aligned}
& w_{\text {hyp }}=\frac{2|f|}{\sqrt{2 \pi}\left(\gamma_{f}+\gamma_{b}\right)} \\
& \times \exp \left[\frac{-f^{2}\left[X\left(\tau-t,\left\{\gamma_{f}, \gamma_{b}, \lambda^{2}\right\}\right)\right]^{2}}{2}\right]
\end{aligned}
$$

where

$$
\begin{aligned}
& X\left(\tau-t,\left\{\gamma_{f}, \gamma_{b}, \lambda^{2}\right\}\right)=\left[\frac{\gamma_{f}+\gamma_{b}}{2 \gamma_{f} \gamma_{b}}\right](\tau-t-\zeta) \\
& +\left[\frac{\gamma_{f}-\gamma_{b}}{2 \gamma_{f} \gamma_{b}}\right] \sqrt{(\tau-t-\zeta)^{2}+\lambda^{2}}
\end{aligned}
$$

In (6) $\gamma_{f}$ and $\gamma_{b}$ are forward-taper and backward-taper parameters, respectively. $\lambda$ denotes the positive curvature parameter and $X$ is hyperbola in $(\tau-t)$ its shape is determined by these parameters. $\zeta$ is defined as:

$$
\zeta=\sqrt{\frac{\left(\gamma_{f}-\gamma_{b}\right)^{2} \lambda^{2}}{4 \gamma_{f} \gamma_{b}}}
$$

However a symmetrical window provides better frequency resolution than an asymmetrical window. So, at high frequencies, where the window is narrow and time resolution is good, a symmetrical window can be used. At low frequencies an asymmetrical window may be used, but as frequency increases, the shape of the window converges toward the Gaussian window.

The ST of a discrete time series $U[k T]$ is given by:

$$
S[n, j]=\sum_{m=0}^{N-1} U(m+n) G(m, n) \exp (i 2 \pi m j)
$$

where $N$ is the total number of samples and $n, m$ and $j$ varies 0 to $N-1$. $U(m, n)$ denotes the frequency shifted discrete Fourier transform $U[m]$, and $G(m, n)$ is the Fourier transform of the hyperbolic window.

\section{THE PROPOSED SCHEME}

In the suggested method, the HST is applied to the differential currents of faulty phases. The time-frequency contours are obtained after HST. It is seen that the time-frequency Contours are interrupted in a consistent time interval in cases of inrush currents but they are interrupted randomly in cases of incipient faults and the contours present consistently in an internal fault. Moreover, the spectral energy and the standard deviation of the S-matrix are calculated. It is found that the spectral energy and the standard deviation of the S-matrix have high values in the cases of internal faults, while they have lower values during inrush currents. Also, the spectral energy and the standard deviation in the incipient fault cases have lower values with respect to inrush currents.

\section{SYSTEM UNDER STUDY}

In order to analyze the performance of the proposed scheme it is implemented in MATLAB environment and tested with simulated fault and inrush cases under EMTP software. The system under study is shown in Fig.1. The simulated transformer is a three phase power transformer with the rating of $100 \mathrm{kVA}, 5500 / 410 \mathrm{~V}$ [12]. The primary winding has 1556 turns wound in 8 layers and the secondary winding has 67 turns wound in 2 layers. The transmission lines have been modeled by $\pi$ sections.

\section{A. Power Transformer Model}

A transformer terminal model can be known in terms of winding resistance, self and mutual inductances. Therefore, $6 \times 6$ RL matrices from BCTRAN routine can be formed for a three phase two winding transformer. Also, $7 \times 7$ and $8 \times 8$ matrices can be derived for turn to ground and turn to turn fault studies in a three phase two winding transformer, respectively [12]. In order to study the turn to turn, the turn to earth and also the internal incipient faults, b-phase of primary winding is divided into three parts with 1148, 97 and 311 turns. Therefore, $8 \times 8$ matrices are considered for the modeled transformer.

\section{B. Internal Incipient Fault Model}

The winding insulation deterioration is a major cause of internal incipient winding faults in transformers. Degradation of the winding insulation is occurred due to 
some factors such as moisture and electrical, thermal and mechanical stresses. Internal incipient fault model is a combination of an aging and an arcing part [13]-[14]. The aging part of the model consists of parallel connected $r_{a g}$ and $c_{a g} \cdot r_{a g}$ and $c_{a g}$ represent the lossy part and capacitance of the dielectric, respectively. The arc occurs when sufficient voltage is across the degraded insulation. The arcing part of the model is represented by a square voltage $(E)$ and a high resistance that increases with time $\left(R_{t}\right)$, connected in parallel.

Various cases such as extinction period, burning period, and non-arcing, can be presented by controlling S1 and $\mathrm{S} 2$. When $\mathrm{S} 1$ is closed and $\mathrm{S} 2$ is open, the model represents the burning period. When S1 and S2 are open, it models the non-arcing period. Otherwise, it represents the extinction period. Fig.2 shows combination of aging and arcing models, connected to transformer winding.

\section{RESUlTS AND DiSCUSSION}

The differential current signals are obtained from secondary side of CTs under various operating conditions, (i.e. internal incipient fault, inrush current, energizing while the internal fault, internal turn to turn and turn to ground faults and internal fault in transformer terminals), fault resistances and inception angles. A sampling rate of $5 \mathrm{kHz}$ is considered for the algorithm, i.e. 100 samples per power frequency cycle based on $50 \mathrm{~Hz}$. Typical time-frequency contours and differential currents at various conditions are shown in Figs.3-10. A typical differential current and it's time-frequency contours for an internal incipient fault between turns 311 and 408, are shown in Fig.3. As it is seen, the contours are presented only during the arcing period and occur randomly and they are not consistent. Fig.4 illustrates the contours for an inrush current. It is found that the contours do not present randomly. They are interrupted but there is a consistent time interval between them. Fig. 5 shows the contours for a turn to turn fault between turns 311 and408. The time-frequency contours for transformer energizing while turn to turn fault occurs between turns 311 and 408, is shown in Fig.6. As it is clear, unlike the inrush current and incipient fault cases, the contours present consistently in Figs.5-6 and they are regular throughout the time. The differential currents and the time-frequency contours for abovementioned cases while contaminated by random noise with SNR up to $20 \mathrm{~dB}$ are illustrated in Figs.7-10, respectively. It is seen that under the noisy conditions, incipient fault, inrush current and internal faults have the same distribution as above described and the contours are influenced little by noise.

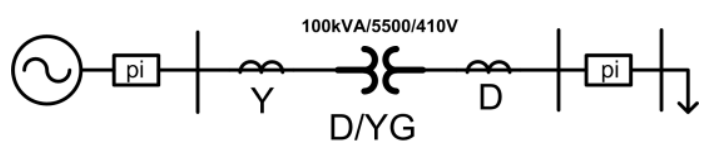

Fig. 1. Simulated system

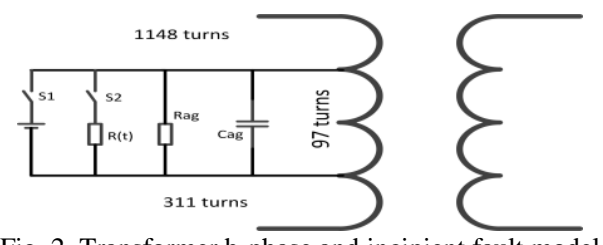

Fig. 2. Transformer b-phase and incipient fault model

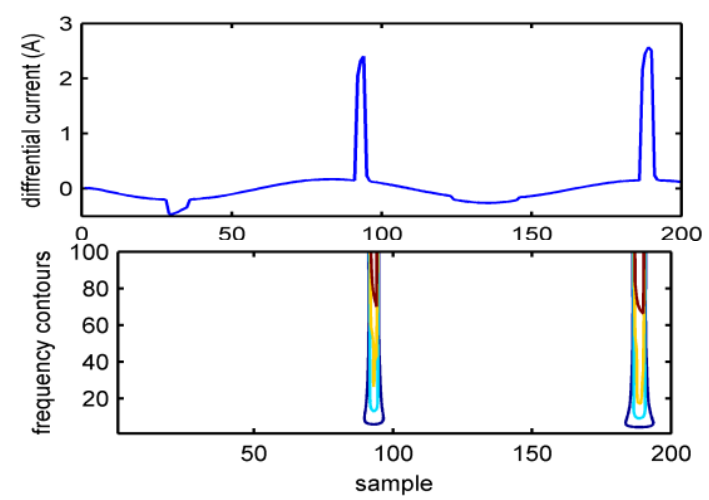

Fig. 3. Differential current and S-contours for internal incipient fault between turns 311 and 408 of primary winding
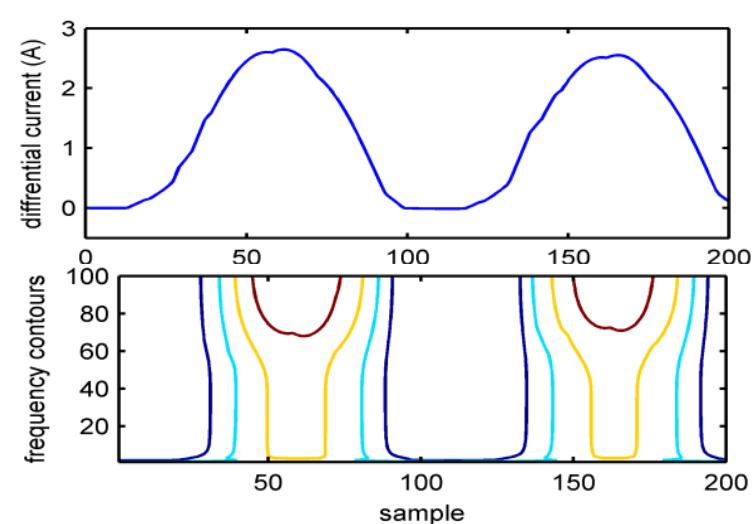

Fig. 4. Differential current and S-contours for an inrush current

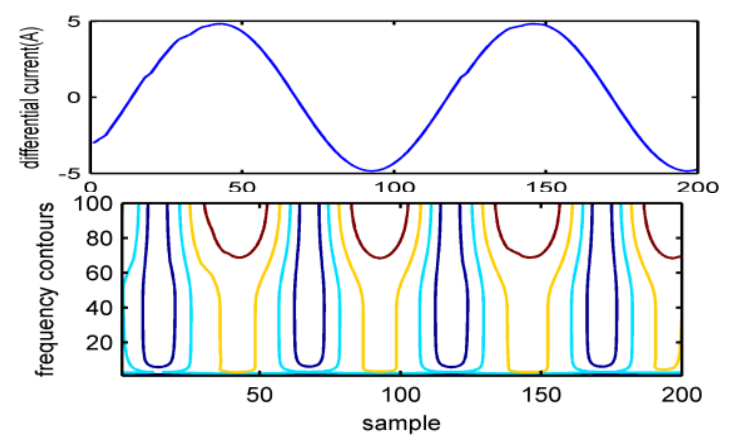

Fig. 5. Differential current and S-contours for turn to turn fault between turns 311 and 408

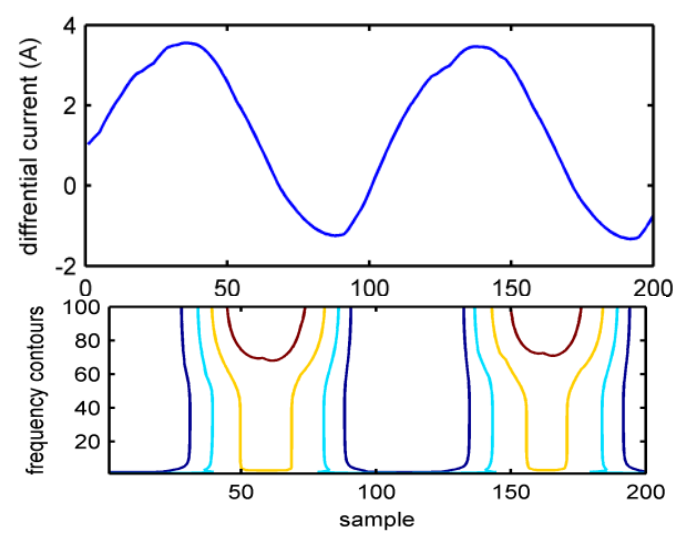

Fig. 6. Differential current and S-contours for transformer energizing while turn to turn fault occurs between turns 311 and 408 . 


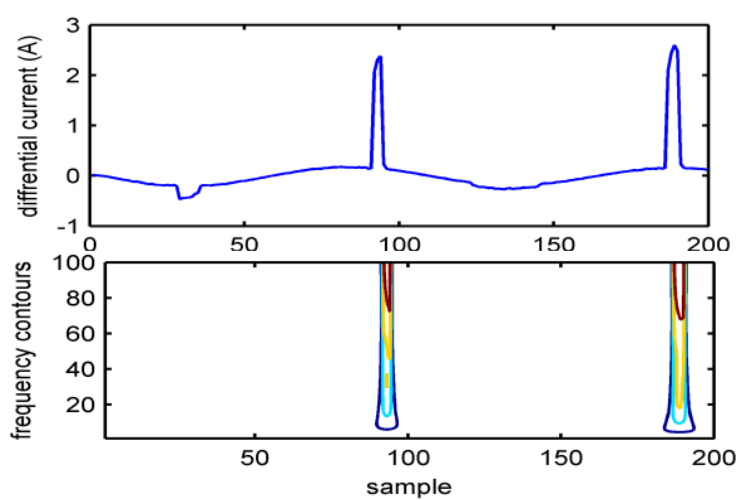

Fig. 7. Differential current with SNR $20 \mathrm{~dB}$ and S-contours for internal incipient fault between turns 311 and 408 of primary winding.

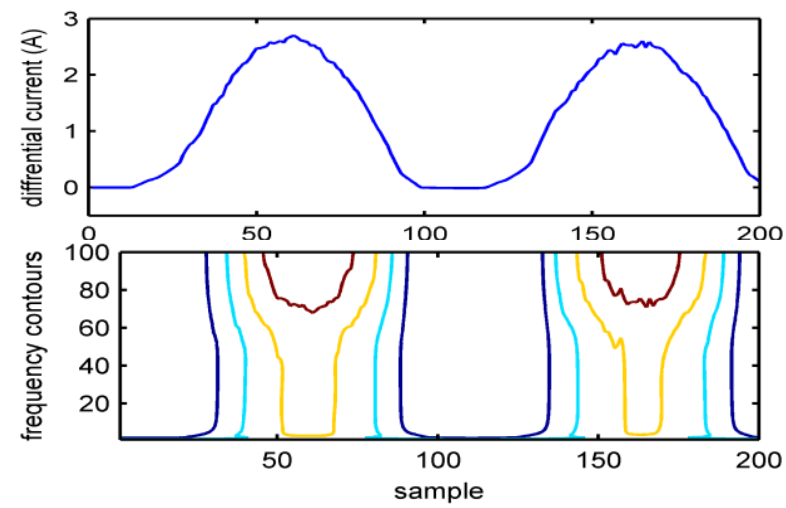

Fig. 8. Differential current with SNR 20dB and S-contours for an inrush current.
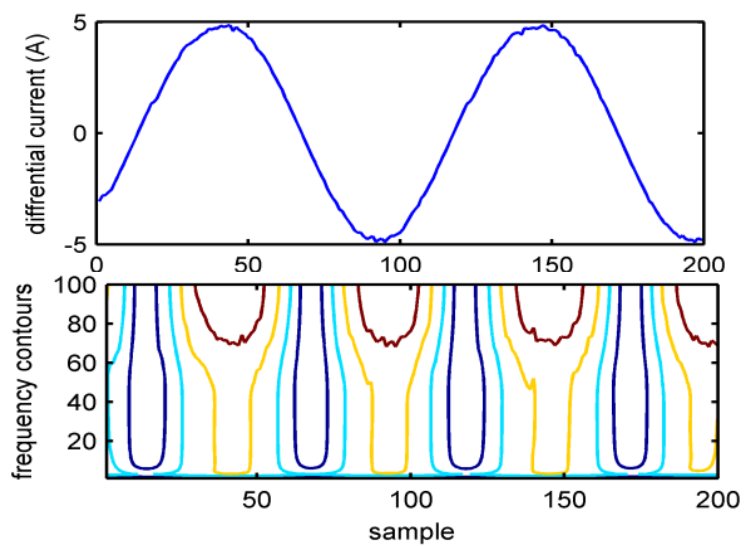

Fig. 9. Differential current with SNR 20dB and S-contours for turn to turn fault between turns 311 and 408

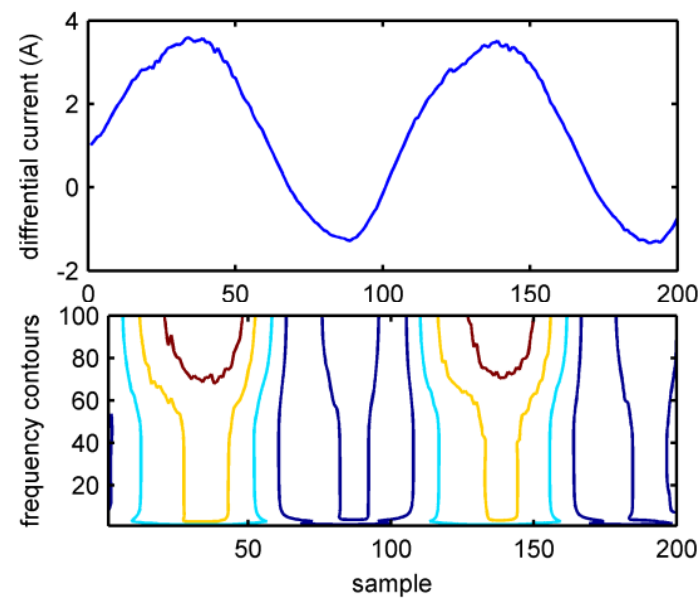

Fig. 10. Differential current with SNR 20dB and S-contours for transformer energizing while turn to turn fault occurs between turns 311 and 408
TABLE.I SIMULATION RESULTS

\begin{tabular}{|c|c|c|c|c|c|c|c|}
\hline \multirow{2}{*}{ fault type } & \multirow{2}{*}{ 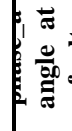 } & \multirow{2}{*}{ 들 } & \multirow{2}{*}{$\begin{array}{l}\stackrel{8}{0} \\
\frac{\tilde{z}}{2}\end{array}$} & \multicolumn{2}{|c|}{ Without noise } & \multicolumn{2}{|c|}{ With noise } \\
\hline & & & & Energy & STD & Energy & STD \\
\hline \multirow{3}{*}{$\begin{array}{c}\text { b-incp } \\
\text { turns } \\
311 \text { to } 408\end{array}$} & \multirow{3}{*}{ no } & \multirow{3}{*}{ no } & A & $1.77 \mathrm{E}+00$ & $5.33 \mathrm{E}-01$ & $1.73 \mathrm{E}+00$ & 5.33E- \\
\hline & & & B & $7.53 \mathrm{E}+01$ & $8.53 \mathrm{E}+00$ & $7.50 \mathrm{E}+01$ & $8.50 \mathrm{E}+\mathrm{C}$ \\
\hline & & & $\mathrm{C}$ & $8.89 \mathrm{E}+01$ & $8.46 \mathrm{E}+00$ & $8.87 \mathrm{E}+01$ & $8.46 \mathrm{E}+\mathrm{C}$ \\
\hline \multirow{3}{*}{$\begin{array}{c}\text { b-incp } \\
\text { turns } \\
311 \text { to } 408\end{array}$} & \multirow{3}{*}{ no } & \multirow{3}{*}{ no } & A & $1.86 \mathrm{E}+00$ & $5.35 \mathrm{E}-01$ & $1.90 \mathrm{E}+00$ & $5.35 \mathrm{E}$ \\
\hline & & & B & $2.33 \mathrm{E}+02$ & $9.86 \mathrm{E}+00$ & $2.34 \mathrm{E}+02$ & $9.92 \mathrm{E}+$ \\
\hline & & & $\mathrm{C}$ & $2.58 \mathrm{E}+02$ & $1.03 \mathrm{E}+01$ & $2.54 \mathrm{E}+02$ & $1.02 \mathrm{E}+0$ \\
\hline \multirow{3}{*}{$\begin{array}{c}\text { b-incp } \\
\text { turns } \\
311 \text { to } 408\end{array}$} & \multirow{3}{*}{ no } & \multirow{3}{*}{ no } & A & $1.72 \mathrm{E}+00$ & $5.35 \mathrm{E}-01$ & $1.72 \mathrm{E}+00$ & 5.37E- \\
\hline & & & B & $2.05 \mathrm{E}+02$ & $9.57 \mathrm{E}+00$ & $2.02 \mathrm{E}+02$ & $9.50 \mathrm{E}+0$ \\
\hline & & & C & $2.29 \mathrm{E}+02$ & $9.95 \mathrm{E}+00$ & $2.32 \mathrm{E}+02$ & $1.00 \mathrm{E}+$ \\
\hline \multirow{3}{*}{ inr noload } & \multirow{3}{*}{45} & \multirow{3}{*}{ no } & A & $7.37 \mathrm{E}+02$ & $3.15 \mathrm{E}+01$ & $7.46 \mathrm{E}+02$ & $3.16 \mathrm{E}+\mathrm{C}$ \\
\hline & & & B & $5.31 \mathrm{E}+02$ & $4.07 \mathrm{E}+01$ & $5.33 \mathrm{E}+02$ & $4.08 \mathrm{E}+01$ \\
\hline & & & C & $5.20 \mathrm{E}+02$ & $2.29 \mathrm{E}+01$ & $5.19 \mathrm{E}+02$ & $2.29 \mathrm{E}+\mathrm{c}$ \\
\hline \multirow{3}{*}{ inr with load } & \multirow{3}{*}{135} & \multirow{3}{*}{ no } & A & $4.06 \mathrm{E}+02$ & $3.20 \mathrm{E}+01$ & $4.06 \mathrm{E}+02$ & $3.21 \mathrm{E}+\mathrm{C}$ \\
\hline & & & B & $8.42 \mathrm{E}+02$ & $2.09 \mathrm{E}+01$ & $8.40 \mathrm{E}+02$ & $2.10 \mathrm{E}+0$ \\
\hline & & & C & $7.55 \mathrm{E}+02$ & $3.94 \mathrm{E}+01$ & $7.55 \mathrm{E}+02$ & $3.95 \mathrm{E}+$ \\
\hline \multirow{3}{*}{$\begin{array}{c}\text { inr } \\
\text { with load }\end{array}$} & \multirow{3}{*}{25} & \multirow{3}{*}{ no } & A & $8.47 \mathrm{E}+02$ & $2.31 \mathrm{E}+01$ & $8.48 \mathrm{E}+02$ & $2.31 \mathrm{E}+$ \\
\hline & & & B & $7.06 \mathrm{E}+02$ & $4.05 \mathrm{E}+01$ & 7.06E+02 & $4.05 \mathrm{E}+\mathrm{C}$ \\
\hline & & & C & 3.65 & $2.82 \mathrm{E}+01$ & $3.66 \mathrm{E}+02$ & $2.82 \mathrm{E}+$ \\
\hline \multirow{3}{*}{$\begin{array}{c}\text { inr with load } \\
\text { and int turns } \\
\text { 311to } 408\end{array}$} & & & A & $5.98 \mathrm{E}+02$ & $2.16 \mathrm{E}+01$ & $6.08 \mathrm{E}+02$ & 2.16E+0 \\
\hline & 0 & 0.5 & B & $5.20 \mathrm{E}+04$ & $8.89 \mathrm{E}+01$ & $5.33 \mathrm{E}+04$ & $8.90 \mathrm{E}+0$ \\
\hline & & & $\mathrm{C}$ & $6.17 \mathrm{E}+04$ & $1.08 \mathrm{E}+02$ & $6.21 \mathrm{E}+04$ & $1.08 \mathrm{E}$ \\
\hline inr noload & & & A & $5.65 \mathrm{E}+02$ & $1.46 \mathrm{E}+01$ & $5.60 \mathrm{E}+02$ & $1.46 \mathrm{E}+$ \\
\hline and int turn & 0 & 2 & B & $7.63 \mathrm{E}+05$ & $3.12 \mathrm{E}+02$ & $7.88 \mathrm{E}+05$ & $3.13 \mathrm{E}+$ \\
\hline 311 to ground & & & C & 1.16 & $1.18 \mathrm{E}+03$ & $1.17 \mathrm{E}+07$ & $1.18 \mathrm{E}+0$ \\
\hline & & & A & $1.83 \mathrm{E}+00$ & $5.23 \mathrm{E}-01$ & $1.84 \mathrm{E}+00$ & 5.23E-01 \\
\hline turns & 45 & 0 & B & $1.83 \mathrm{E}+06$ & $4.84 \mathrm{E}+02$ & $1.83 \mathrm{E}+06$ & $4.84 \mathrm{E}+0$ \\
\hline 311 to 408 & & & $\mathrm{C}$ & $1.84 \mathrm{E}+06$ & $4.85 \mathrm{E}+02$ & $1.83 \mathrm{E}+06$ & $4.85 \mathrm{E}+0$ \\
\hline & & & A & $1.97 \mathrm{E}+00$ & $5.31 \mathrm{E}-01$ & $1.98 \mathrm{E}+00$ & $5.31 \mathrm{E}-0$ \\
\hline rns & 145 & 1 & B & $1.44 \mathrm{E}+05$ & $9.38 \mathrm{E}+01$ & $1.44 \mathrm{E}+05$ & $9.38 \mathrm{E}+0$ \\
\hline 311 and 408 & & & C & $1.45 \mathrm{E}+05$ & $9.43 \mathrm{E}+01$ & $1.46 \mathrm{E}+05$ & $9.43 \mathrm{E}+\mathrm{C}$ \\
\hline int & & & A & $1.60 \mathrm{E}+00$ & $4.75 \mathrm{E}-01$ & $1.57 \mathrm{E}+00$ & $4.75 \mathrm{E}-0$ \\
\hline urn & 145 & 7 & B & $2.09 \mathrm{E}+05$ & $1.55 \mathrm{E}+02$ & $2.13 E+05$ & $1.55 \mathrm{E}+0$ \\
\hline 311 to ground & & & $\mathrm{C}$ & $3.34 \mathrm{E}+06$ & $6.19 \mathrm{E}+02$ & $3.38 \mathrm{E}+06$ & $6.20 \mathrm{E}+02$ \\
\hline & & & A & $1.73 \mathrm{E}+00$ & $4.52 \mathrm{E}-01$ & $1.69 \mathrm{E}+00$ & 4.52E-01 \\
\hline rn & 90 & 5 & B & $1.26 \mathrm{E}+06$ & $2.22 \mathrm{E}+02$ & $1.31 E+06$ & $2.22 \mathrm{E}+02$ \\
\hline 408 to ground & & & $\mathrm{C}$ & $9.97 \mathrm{E}+06$ & $6.23 \mathrm{E}+02$ & $9.94 \mathrm{E}+06$ & $6.22 \mathrm{E}+0$ \\
\hline terminal & & & $\mathbf{A}$ & $2.09 \mathrm{E}+06$ & $5.86 \mathrm{E}+02$ & $2.09 E+06$ & $5.86 \mathrm{E}+02$ \\
\hline ac & 15 & 0 & B & $5.22 \mathrm{E}+05$ & $2.93 \mathrm{E}+02$ & $5.30 \mathrm{E}+05$ & $2.93 E+02$ \\
\hline & & & $\mathrm{C}$ & $5.20 \mathrm{E}+05$ & $2.93 \mathrm{E}+02$ & $5.22 \mathrm{E}+05$ & $2.92 \mathrm{E}+02$ \\
\hline
\end{tabular}


Various types of incipient faults and internal faults with different resistances and fault angles as well as various energizations with different switching angles were simulated. The results for some cases are given in Table.I. The spectral energy and the standard deviation from the HST of the differential current signals are calculated. It is found that the standard deviation and so the spectral energy of the $\mathrm{S}$-matrix in the faulty phases have high values and they have lower values in the cases of inrush currents. Also, it can be seen that the standard deviation and spectral energy in the incipient faults cases are lower than the inrush current cases. So, it is easy to discriminate truly between inrush currents, incipient and internal faults.

In the presented cases, the spectral energy values in the faulty phases are between 5.20E+04 and 1.16E+07. But it ranges approximately between $3.65 \mathrm{E}+02$ and $8.47 \mathrm{E}+02$ in the inrush current cases and its values in the incipient fault cases are between $7.53 \mathrm{E}+01$ and $2.58 \mathrm{E}+02$, in the faulty phases. The standard deviation ranges between $8.89 \mathrm{E}+01$ and $1.18 \mathrm{E}+03$ in the internal fault cases and it is between $2.09 \mathrm{E}+01$ and $4.07 \mathrm{E}+01$ in the inrush cases, and it varies from $8.46 \mathrm{E}+00$ to $1.03 \mathrm{E}+01$ in the cases of internal incipient faults. The turn to turn, turn to earth and the incipient faults are simulated in b-phase. Since the primary windings are connected as delta, high values are performed in $\mathrm{b}$ and $\mathrm{c}$ phases in fault cases. If there is not any transient phenomenon, there is no differential current and the scheme is not performed.

In order to study the robustness of the method in noisy environments, random noise with SNR up to $20 \mathrm{~dB}$ has been added to the differential currents. As it is shown in Table.I, the spectral energy and the standard deviation of the S-matrix are influenced little by noise.

\section{CONCLUSION}

A new scheme for distinguishing different transient currents in transformers is suggested, focused on internal incipient current. The standard deviation and the spectral energy of the S-matrix of the differential currents are calculated. Then, faults can be detected by comparison of the standard deviation and the spectral energy of the faulty phases with threshold values. The proposed algorithm was implemented in MATLAB environment and tested using simulation resulted from the EMTP software. Several cases have been studied to test the performance of the technique. The signals are contaminated with noise and the performance of the algorithm in noisy environment is studied. The simulation results indicate the robustness of the proposed technique even in the noisy environments.

\section{REFERENCES}

[1] K. L. Butler-Puny and H. Wang, "Computer models of internal short circuit and incipient faults in transformers," Transmission and Distribution Conference and Exposition,2003, pp.1027-1027.

[2] C. E. lin, J. M. Ling, and C. L. Huang, "Expert system for transformer fault diagnosis using dissolved gas analysis," IEEE Trans. On Power Del, vol. 8, no. 1, pp. 231-238, Jan. 1993.

[3] A. Nosseir, A. S. Attia, F. Tahoon, and N. M. Osman, "A fast and reliable transformer protection system based on the transformer magnetizing characteristics and artificial neural networks," IEEE Power System Conference, Aswan. Mar12-15, pp.511-516. 2008.
[4] H. Kazemi Kargar, M. Jabbari, and S. Golmohammad zadeh, "Inrush current identification based on wavelet transform and correlation factors," $6^{\text {th }}$ International Conference on Telecommunication and Technology, 2009.

[5] K. L. Butler-Purry and M. Bagriyanik, "Identifying transformer incipient events for maintaining distribution system reliability," in Proc. the $36^{\text {th }}$ Annual International Conference on System Sciences, Hawaii, pp.1-8. 2003.

[6] M. S. Naderi, G. B. Gharehpetian, and M. Abedi, "Modeling and detection of transformer internal incipient fault during impulse test," IEEE Trans. On dielectrics and electrical insulation, vol. 15, no. 1, pp.284-291, Feb.2008.

[7] Q. Zhang, S. Jiao, and S. Wang, "Identification inrush current and internal faults of transformer based on Hyperbolic S-transform," $4^{\text {th }}$ IEEE Conference on Industrial Electronics and Applications, pp.258-263, 2009.

[8] K. Panigrahi, S. R Samantaray, P. K. Dash, and G. Panda, "Discrimination between inrush current and internal faults using pattern recognition approach," International Conference on Power Electronics, Drives and Energy Systems, 2006.

[9] S. Sendilkumar and B. L. Mathur, J. Henry, "A new technique to classify transient events in power transformer differential protection using S-transform," 3th International Conference on Power Systems, Kharagpur, INDIA, Dec 27-29. pp.1-6. 2009.

[10] S. Jia, S. Wang, and G. Zheng, "A new approach to identify inrush current based on generalized S-transform," International Conference on Electrical Machines and Systems, 2008, pp 4317-4322.

[11] R. G. Stockwell, L. Mansinha, and R. P. Lowe, "Localization of the complex spectrum: the S transform," IEEE Trans. On signal processing, vol.44, no.4, pp.998-1001, Apr 1996.

[12] P. Bastard, P. Bertrand, and M. Meunier, "A transformer model for winding fault studies," IEEE Trans.Power Del.,vol. 9. no. 2, pp.690-699, Apr 1994.

[13] Nehmdoh, A. Sabihaand, and M. A. Izzularab, "Transformer modeling with internal incipient," $11^{\text {th }}$ International Middle East Power Systems Conference , Dec 19-21, 2006, pp.117-122.

[14] H. Wang and K. L. Butler, "Modeling transformers with internal incipient faults," IEEE Trans. On Power Del., vol. 17, no. 2, pp.500-509, Apr 2002.

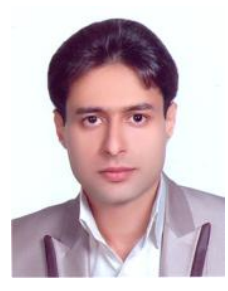

A. Ashrafian was born in Dezfoul, Iran in 1985. He received his B.S and M.S.C degrees in electrical power engineering from Islamic Azad University, South Tehran branch, Tehran, Iran, in 2008 and Department of Engineering, Shahed University, Tehran, Iran, in 2011, respectively. He serves as lecturer in Department of Engineering, Shahed University, Tehran, Iran and Department of Engineering, Shahre-rey branch, Islamic Azad University, Tehran, Iran.

He has been the author of several papers published in journals and presented at national and international conferences. His research interests include transient analysis of power system, digital signal processing, power system protection and relaying, transformer dielectric testing and power quality monitoring.

Mr. Ashrafian is a member of IEEE.

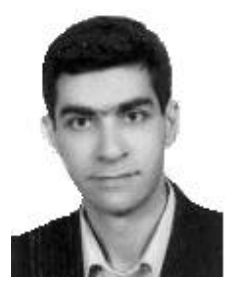

Mehrdad Rostami received his BS, MS and Ph.D. degrees in electrical engineering in 1989, 1992 and 2003 from Amirkabir University of Technology (AUT).

He is the author of more than 60 papers in journals and conferences. Being IEEE member, he has been involved in reviewing several journal and conference papers in his field (Transient, Reliability, Chaos and Ferro resonance in power system). He has been assistant professor of Shahed University since 2004 and has been nominated to upgrade to associate Professor recently.

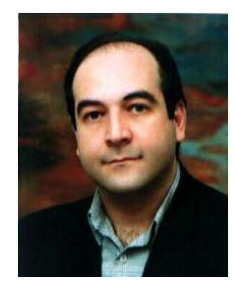

G. B. Gharehpetian received his BS, MS and Ph.D. degrees in electrical engineering in 1987, 1989 and 1996 from Tabriz University, Tabriz, Iran and Amirkabir University of Technology (AUT), Tehran, Iran and Tehran University, Tehran, Iran, respectively, graduating all with First Class Honors. As a Ph.D. student, he has received scholarship from DAAD (German Academic Exchange Service) from 1993 to 1996 and he was with High Voltage Institute 
of RWTH Aachen, Aachen, Germany. He has been holding the Assistant Professor position at AUT from 1997 to 2003, the position of Associate Professor from 2004 to 2007 and has been Professor since 2007. The power engineering group of AUT has been selected as a Center of Excellence on Power Systems in Iran since 2001. He is a member of this center. He is the author of more than 450 journal and conference papers. His teaching and research interest include power system and transformers transients and power electronics applications in power systems.

Prof. Gharehpetian was selected by the ministry of higher education as the distinguished professor of Iran and by IAEEE (Iranian Association of Electrical and Electronics Engineers) as the distinguished researcher of Iran and was awarded the National Prize in 2008 and 2010, respectively. $\mathrm{He}$ is a senior and distinguished member of IEEE and IAEEE, respectively, and a member of the central board of IAEEE. Since 2004, he is the Editor-in-Chief of the Journal of IAEEE.

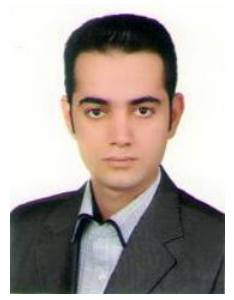

Seyed Sajad Shafiee Bahnamiri was born in Babolsar, Iran, in 1986. He received his B.Sc. and M.Sc. degrees both in electrical engineering from Islamic Azad University, Tehran jonob branch, Tehran, Iran in 2008 and Shahed University, Tehran, Iran in 2011, respectively. He is currently a part-time lecturer at the Shahed University, Tehran, Iran, And Islamic Azad University, Joubar Branch, Joubar, Iran. His research interests include power quality, power electronics, reliability, STS (Static Transfer Switch), frequency response analysis and their applications into power system. 